\title{
Sistem Online M0nitoring Besaran Listrik 3 Fasa Berbasis Single Board Computer BCM 8235
}

\author{
Yusuf Yoekie Permadi ${ }^{1}$, Dr.Eng,Dikpride Despa,S.T.,M.T ${ }^{2)}$, M. Komarudin,S.T.,M.T ${ }^{3)}$ \\ 1,2,3 Jurusan Teknik Elektro Universitas Lampung, Bandar Lampung \\ Jl. Prof. Sumantri Bojonegoro No. 1 Bandar Lampung 35145 \\ vupermadi01@gmail.com
}

\begin{abstract}
ABSTRAK - Besaran listrik 3 fasa perlu dimonitor untuk mengetahui nilai besaran listriknya tegangan (V), arus (A), faktor daya (Cos $\theta)$, daya (W) dan konsumsi energi (kWh). Sehingga dapat diketahui untuk mengetahui kualitas pasokan energi listriknya.

Sistem monitoring yang dimaksud pada penelitian ini adalah pengukuran tegangan dan arus sedangkan nilai daya dan faktor daya didapat dari hasil perhitungan menggunakan program bahasa $C$ yang di arduino sedangkan untuk perhitungan konsumsi energi/kWh dibuat pemograman python pada BCM 2835. Tugas akhir ini membuat sebuah prototype sistem monitoring yang telah diperoleh pada gedung laboratorium jurusan Teknik Elektro dan gedung UPT - TIK Universitas Lampung. Dari data yang diperoleh pada tanggal 30 juni 2016 didapat hasil nilai besaran listrik antar phasa: tegangan, arus dan daya pada ke dua gedung cenderung tidak seimbang, hal ini disebabkan karena pola pembebanan masing-masing phasa pada gedung yang dianalisa tidak merata. Sedangkan untuk nilai faktor daya pada setiap gedungnya bergantung pada beban.
\end{abstract}

Kata kunci : listrik 3 fasa, sensor tegangan, sensor arus, Arduino, Single Board Computer BCM 2835.

ABSTRACT - Three phase electrical quantities need to be monitored for determine the value of the electrical voltage $(V)$, current $(A)$, power factor $(\cos \theta)$, power $(W)$ and energy consumption $(k W h)$. So it can be determine the quality of the electrical supply energy.

Monitoring system in this thesis describe the measurement of voltage and current while the power and power factor value obtained from the calculation using the Clanguage program at arduino where as for the calculation of energy consumption / $k W h$ made by python programming at BCM 2835.

This Thesis is to create a prototype for monitoring system that has been obtained at the laboratory and Department of Electrical Engineering Unit - ICT buildings, University of Lampung. From the data obtained on 30 June 2016 the results of the inter-phase electrical quantities: voltage, current and power on to the two buildings tend to be unbalanced, because the loading pattern of each phase in the building which analyzed was uneven. For the value of the power factor at every building is depends on the load.

Keywords: electric 3 phase, voltage sensors, flow sensors, Arduino, Single board Computer BCM 8235.

\section{PENDAHULUAN}

Energi listrik sangat berperan penting dalam memajukan perekonomian masyarakat, banyak peralatan yang membutuhkan energi listrik untuk mengoperasikannya, baik dalam skala rumah tangga maupun skala industri perlu dibuat sebuah sistem monitoring besaran listrik yang meliputi tegangan, arus, faktor daya, dan daya listrik yang dapat digunakan sebagai bahan alanisa. Untuk memenuhi kebutuhan di atas, perlu dibuat sebuah prototype monitoring besaran listrik. Saat ini monitoring besaran listrik banyak dilakukan dengan cara memasang alat-alat ukur listrik pada panel listrik sebelum masuk ke beban, cara ini memiliki kekurangan diantaranya adalah yang pertama untuk mengetahui status kelistrikan harus langsung melihat di lokasi tempat alat ukur dipasang sehingga akan sangat merepotkan dan yang kedua adalah dengan cara ini hanya dapat dilihat

besaran listrik pada saat itu saja, tidak ada rekaman monitoring yang dapat digunakan sebagai bahan alanisa. Pada penelitian ini membuat hardware yang mampu memonitoring sistem kelistrikan tiga fasa pada dua gedung yang berbeda yakni panel gedung Laboratorium Terpadu Jurusan Teknik Elektro dan panel listrik Unit Pelayanan Terpadu Teknologi Informasi dan Komunikasi Universitas Lampung, alat ini dapat memonitoring besaran besaran listrik yang aman bagi sistem kelistrikan dan menapilkanya dalam bentuk grafik dalam sebuah Prototype sistem online monitoring ${ }^{[1]}$. 


\section{TINJAUAN PUSTAKA}

\subsection{Besaran Listrik $^{[2]}$}

Pada dunia kelistrikan, dikenal beberapa besaran listrik yang penting untuk diketahui, diantaranya adalah arus, tegangan dan daya. Arus listrik adalah banyaknya muatan yang mengalir pada sebuah penghantar dalam waktu satu detik (coulombs per second) yang diukur dalam satuan ampere (A). Arus listrik dapat dirumuskan dengan persamaan berikut :

$$
\mathbf{I}=\frac{\mathbf{Q}}{\mathbf{t}}
$$

$$
\begin{aligned}
\text { Dimana : I } & =\text { Arus listrik ampere (A) } \\
\mathrm{Q} & =\text { Muatan listrik coulomb }(\mathrm{C}) \\
\mathrm{t} & =\text { Waktu dalam satuan detik (s) }
\end{aligned}
$$

Daya listrik adalah banyaknya energi listrik yang mengalir setiap detik atau joule per second yang diukur dalam satuan watt (W). Daya listrik dirumuskan dengan persamaan berikut ${ }^{[2]}$ :

$$
\mathbf{E}=\text { P.t }
$$

$$
P=\frac{E}{t}
$$

Dimana : $\mathrm{P}=$ Daya dalam satuan watt $(\mathrm{W})$

$\mathrm{E} \quad=$ Energi dalam satuan joule $(\mathrm{J})$

$\mathrm{t} \quad=$ Waktu dalam satuan detik (s)

Energi listrik dapat juga didefinisikan sebagai laju penggunaan daya listrik dikalikan dengan selama waktu tersebut. Satuan SI untuk energi listrik adalah Joule (J), namun dalam kehidupan seharihari lebih dikenal dengan kilo watt hour $(\mathrm{kWh})^{[3]}$.

Selanjutnya hubungan arus, tegangan dan daya dijelaskan dengan persamaan berikut :

$\mathbf{P}=\mathbf{I} \mathbf{V}$

$$
\mathbf{P}=\mathbf{I}^{\mathbf{2}} \mathbf{R}
$$

$$
\mathbf{I}=\frac{\mathbf{P}}{\mathbf{V}}
$$

$\mathbf{V}=\frac{\mathbf{P}}{\mathbf{I}}$

Pada jaringan listrik AC dengan bentuk gelombang sinusoidal dikenal beberapa jenis bentuk daya, diantaranya adalah daya kompleks, daya aktif dan daya reaktif. Perkalian tegangan $\mathrm{V}$ dengan arus I* dalam kedua besaran ini dalam bentuk kompleks adalah VI* yang dinamakan daya kompleks dengan simbol S, dalam satuan Volt Ampere (VA).
Daya aktif atau daya nyata dirumuskan dengan $\mathrm{S}$ $\cos \theta$ atau $\mathrm{VI}^{*} \cos \theta$ dengan simbol $\mathrm{P}$, dalam satuan Watt (W). Sedangkan daya reaktif atau daya khayal dirumuskan dengan $\mathrm{S} \sin \theta$ atau $\mathrm{VI}^{*} \sin \theta$ dengan simbol $Q$, dalam satuan Volt Ampere Reaktif (VAR) ${ }^{[3]}$.

Hubungan antara ketiga jenis daya diatas dapat dijelaskan dengan sketsa segitiga daya seperti ditunjukkan pada Gambar 2.1 berikut $^{[3]}$ :

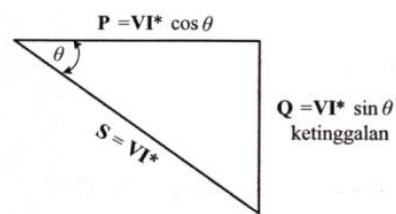

Bersifat induktif.

Bersifat kapasitif.

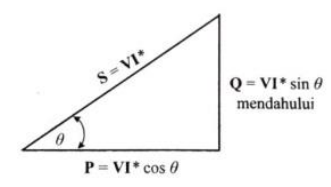

Gambar 1. Segitiga Daya

Komponen-komponen segitiga daya dapat dituliskan sebagai berikut:
Daya aktif
$: \mathrm{P}=\mathrm{VI}^{*} \cos \theta(\mathrm{W})$
Daya reaktif
$: \mathrm{Q}=\mathrm{VI}^{*} \sin \theta(\mathrm{VAR})$
Daya kompleks
$: \mathrm{S}=\mathrm{VI} *$ (VA)

Faktor daya : p.f $=\cos \theta$

Dengan adanya sudut fasa $\theta$ maka akan muncul sebuah besaran yang disebut Faktor daya atau power factor (p.f) yang merupakan nilai cosinus dari besar sudut fasa $\theta^{[3]}$.

\subsection{Pengukuran Tegangan Tinggi AC}

Untuk melakukan pengukuran tegangan tinggi AC, metode yang digunakan adalah dengan cara menurunkan tegangan tinggi ke tegangan rendah. Metode ini yang digunakan dalam pembuatan alat ukur tegangan atau Voltmeter. Untuk menurunkan tegangan dapat dilakukan dengan cara, yaitu dengan menggunakan rangkaian pembagi tegangan atau yang kedua dengan menggunakan transformator step down.

Transformator yang baik untuk digunakan sebagai sensor tegangan adalah transformator yang memiliki sifat linieritas yang baik ${ }^{[3]}$.

\subsection{Pengukuran Arus $\mathrm{AC}^{[20]}$}

Sensor arus adalah perangkat yang mendeteksi arus listrik (AC atau DC) di kawat, dan menghasilkan sinyal sebanding dengan itu. Sinyal yang dihasilkan bisa tegangan analog atau arus atau bahkan digital. Hal ini dapat kemudian 
digunakan untuk menampilkan arus yang akan diukur dalam ammeter atau dapat disimpan untuk analisis lebih lanjut dalam sistem akuisisi data atau dapat dimanfaatkan untuk tujuan kontrol.Sensor arus digunakan untuk menyensor arus yang menuju beban (misalnya: 0-5 Amper) diubah menjadi tegangan 0-5 Volt. Karena sensor arus ini digunakan untuk menyensor arus yang menuju beban, maka lilitannya dirancang untuk dihubungkan secara seri dengan saluran seperti dalam Gambar Oleh sebab itu impedansi lilitan primer perlu dibuat serendah mungkin dengan menggunakan beberapa liitan kawat bertahanan rendah yang mampu membawa arus saluran yang nilainya tertentu. Perbandingan arus primer dan sekunder adalah berbanding terbalik dengan perbandingan jumlah lilitan primer dan sekunder ${ }^{[7]}$.

\subsection{Arduino}

Arduino UNO adalah sebuah board mikrokontroler yang didasarkan pada ATmega328. Arduino UNO mempunyai 14 pin digital input/output (6 di antaranya dapat digunakan sebagai output PWM), 6 input analog, sebuah osilator Kristal $16 \mathrm{MHz}$, sebuah koneksi USB, sebuah power jack, sebuah ICSP header, dan sebuat tombol reset. Arduino UNO memuat semua yang dibutuhkan untuk menunjang mikrokontroler, mudah menghubungkannya ke sebuah computer dengan sebuah kabel USB atau mensuplainya dengan sebuah adaptor AC ke DC atau menggunakan beterai[8].

\subsection{Single Board Computer BCM2835 (Raspberry} $\mathrm{Pi})^{[21]}$

Single Board Computer BCM2835 (Gambar 2.10) atau biasa disebut dengan raspberri pi adalah komputer berukuran kartu kredit yang dikembangkan oleh single board computer BCM 8235 foundation, yang memiliki fungsi yang hampir sama dengan PC kebanyakan. Model PC ini dibagi menjadi dua tipe, yaitu tipe A dan tipe B. Perbedaan keduanya hanya terletak pada memory, jumlah port USB, dan network adaptor.

Pada Single board computer BCM 2835 dilengkapi dengan General Purpose Input/Output (GPIO), setiap pin dari GPIO ini dapat diatur sebagai masukan atau keluaran. Melalui GPIO, Single board computer BCM 2835 dapat menerima berbagai macam masukan untuk dilakukan pemrograman, masukan dapat berupa berbagai macam sensor seperti sensor suhu, sensor cahaya, sensor tegangan dan lain sebagainya[9].

\section{METODE PENELITIAN}

Langkah-langkah dalam Penelitian ini dapat dilihat pada gambar 2 dibawah ini.

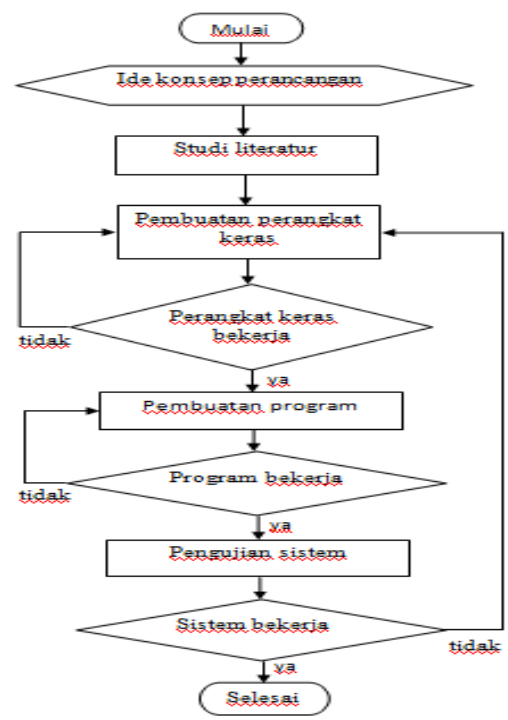

Gambar 2. Diagram alir pelaksanaan tugas akhir.

\subsection{Blok Diagram Sistem}

Untuk mempermudah dalam memahami sistem maka dibuat blok diagram sistem yang ditunjukkan pada Gambar 3 berikut :

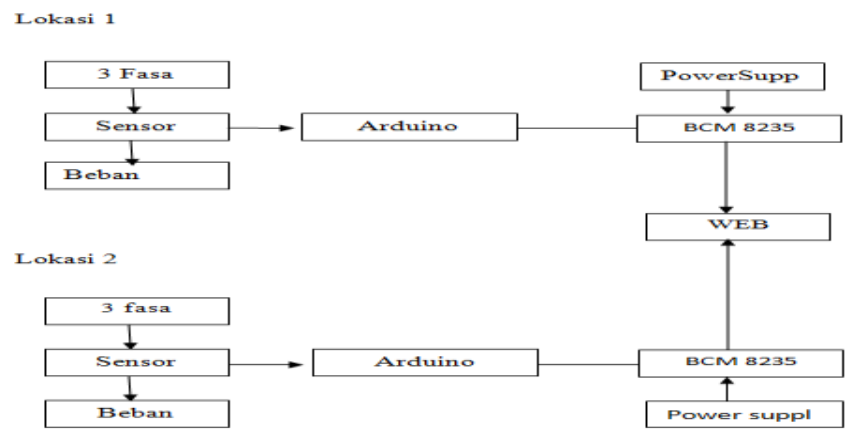

Gambar 3. Blok Digram Sistem

Untuk membuat sistem monitoring besaran listrik ini, alurnya adalah yang pertama dari sumber listrik 3 fasa masuk ke sensor arus dan sensor tegangan, selanjutnya dihubungkan kebeban listrik yang digunakan. Hasil pembacaan sensor arus dan sensor tegangan akan diolah oleh arduino untuk mendapatkan semua besaran listrik yang diinginkan. Selanjutnya data yang di dapat dari arduino dikirim ke Single board computer BCM 2835 menggunakan jalur LAN. Single board computer BCM 2835 merupakan tempat membuat program untuk menyimpan hasil monitoring kedalam data base dan menampilkannya dalam bentuk grafik. 


\subsection{Perancangan Sistem}

Perancangan sistem dari penelitian ini meliputi :

a. Perancangan sensor tegangan dan sensor arus

Dalam perancangan sensor tegangan digunakan transformator step-down untuk menurunkan tegangan dari level tegangan tinggi ke level tegangan rendah. Keluaran trafo masih berupa tegangan $\mathrm{AC}$ sehingga dibutuhkan rangkaian pengkondisian sinyal agar di dapat tegangan yang aman bagi Arduino rangkaian sensor tegangan yang akan dibuat ditunjukkan pada Gambar 4.

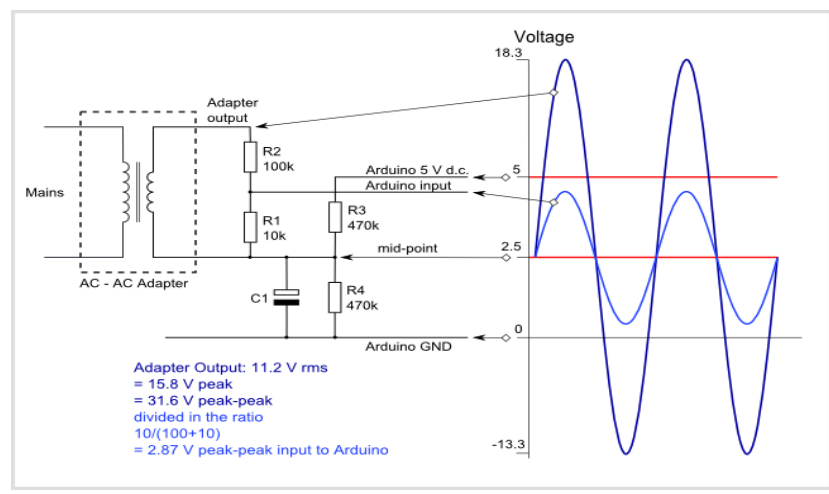

Gambar 4. Rangkaian Sensor Tegangan.

Sensor arus menggunakan seri SCT-013 $100 \mathrm{~A}$, sensor ini akan memberikan tegangan output yang linier dengan perubahan arus yang diukur. Sinyal keluaran SCT-013 100A tergantung sinyal masukan, jika arus yang diukur adalah arus AC maka sinyal keluaran merupakan sinyal AC dan jika arus yang diukur adalah arus DC maka sinyal keluaran merupakan sinyal DC. Pada penelitian ini arus yang akan diukur adalah arus AC sehingga perlu ditambahkan rangkaian pengkondisian sinyal agar aman bagi arduino. Rangkaian sensor yang akan dibuat ditunjukkan pada Gambar 5.

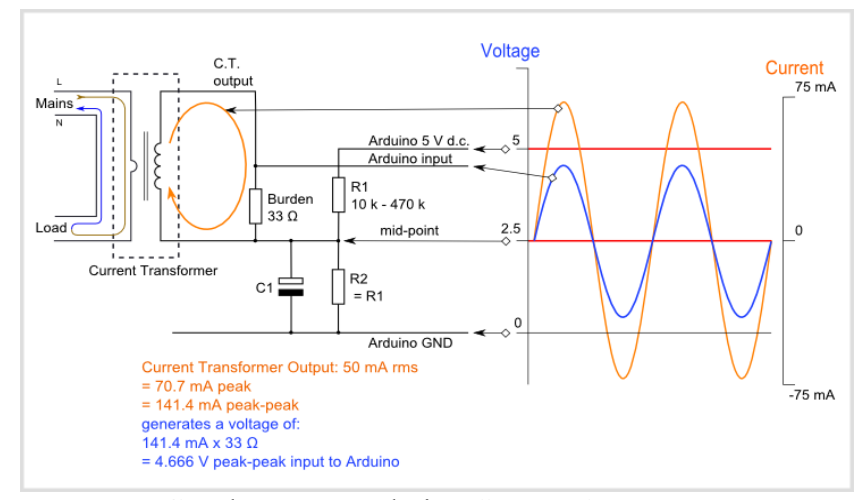

Gambar 5. Rangkaian Sensor Arus.

b. Pembuatan program

Pemoggraman yang di buat dibedakan menjadi dua bagian, yang pertama pemograman dengan menggunakan bahasa $\mathrm{C}$ yang di buat pada arduino untuk membaca sensor tegangan dan sensor arus yang terpasang untuk mendapatkan nilai dari semua besaran listrik dan menggunakan bahasa pemoggraman phyton pada BCM 2835 untuk menampilkan dan menyimpan database.

\subsection{Kalibrasi.}

Untuk menggunakan sebuah alat ukur digital persentase kesalahan haruslah kecil dan sensorsensor yang digunakan harus sangat mendukung dalam tugas akhir ini, pemograman menggunakan pemograman python yang di buat pada single board computer BCM 2835 untuk membaca data dari Arduino kemudian mengirimkan data tersebut kedalam sebuah database untuk di tampikan ke web dalam bentuk grafik. keluarannya masih berupa nilai tegangan yang relative kecil, sehingga nilai tersebut belum dapat menunjukkan nilai besaran yang diukur. Untuk melakukan kalibrasi, menggunakan ala tukur digital yang sudah ada menggunkan Digital Power Clamp Meter.

\section{HASIL DAN PEMBAHASAN}

\subsection{Pembuatan Perangkat Keras}

Dalam pembuatan perangkat keras ini membutuhkan dua buah alat yang masing-masing sama prinsip kerjanya dikarenakan akan dipasang bersamaan pada panel listrik pada dua gedung yang berbeda. Maka dilakukan langkah-langkah yang pertama adalah menyediakan sensor tegangan dan sensor arus yang masing-masing membutuhkan 3 buah. Sensor tegangan menggunakan Trafo step-down ukuran 3 Ampere dan sensor arus menggunakan sensor arus CT 100A kedua alat tersebut membutuhkan rangkaian pengkondisian sinyal agar keluarannya dapat diterima oleh Raspberry Pi dan arduino. Gambar 6. merupakan rangkaian pengkondisian sinyal yang telah dibuat :

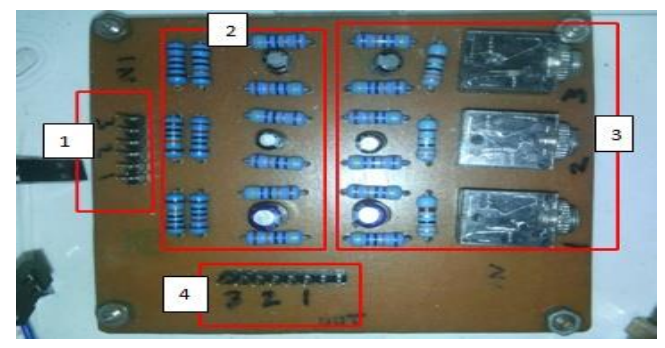

Gambar 6. Rangkaian pengkondisian sinyal

Keterangan Gambar 4.1 :

$1=$ In-put sensor tegangan

$2=$ Rangkaian pengkondisian sinyal sensor tegangan

3 = Rangkaian pengkondisian sinyal sensor arus 
4 = Out-put pengkondisian sinyal sensor tegangan dan sensor arus.

Langkah selanjutnya adalah merancang perangkat keras secara keseluruhan dengan menggabungkan piranti-piranti alat prototype sistem ini dan kemudian dikemas ke dalam Box MCB khusus supaya terlihat lebih rapi.

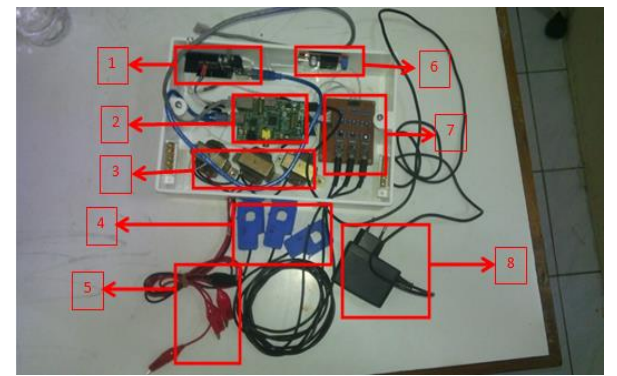

Gambar 7. Hardware Sistem Monitoring Besaran Listrik.

Ketrangan gambar :

1. Arduino UNO

2. Raspberry Pi (Single Board Computer BCM2835)

3. Trafo $3 \mathrm{~A}$

4. Sensor Arus CT 100A

5. Jack sensor tegangan

6. Converter DC to DC

7. Rangkaian pengkondisian sinyal

8. Adaptor raspberry Pi.

\subsection{Pengujian Alat dan Data Hasil Pengujian}

Pengujian alat ini dilakukan untuk menguji keandalan dan keakuratan sebuah alat sebelum di aplikasikan pada panel-panel gedung, dalam pengujian tugas akhir alat ini dilakukan di laboratorium instrumen dan pengukuran.

Pengujian alat ini diuji dengan beban yang berbeda-beda yaitu kipas angin, lampu dan setrika. Setelah itu akan membadingkan hasil pengukuran sebuan alat dengan alat ukur. Di bawah ini adalah perbandingan pengujian alat prototype sistem dengan alat ukur power clamp multitester digital.

Tabel 4.1 Data Hasil Pengujian Alat

\begin{tabular}{|c|c|c|c|c|c|c|c|c|c|}
\hline \multirow[t]{3}{*}{ No } & \multirow[t]{3}{*}{ Beban } & \multicolumn{8}{|c|}{ Data Hasil Pengukuran } \\
\hline & & \multicolumn{2}{|c|}{ Volt (v) } & \multicolumn{2}{|c|}{ Ampere (I) } & \multicolumn{2}{|c|}{$\operatorname{Pf}(\cos \theta)$} & \multicolumn{2}{|c|}{ Daya(Watt) } \\
\hline & & $\begin{array}{l}\text { Uji } \\
\text { alat }\end{array}$ & $\begin{array}{l}\text { Alat } \\
\text { ukur }\end{array}$ & $\begin{array}{l}\text { Uji } \\
\text { alat }\end{array}$ & $\begin{array}{l}\text { Alat } \\
\text { ukur }\end{array}$ & $\begin{array}{l}\text { Uji } \\
\text { alat }\end{array}$ & $\begin{array}{l}\text { Alat } \\
\text { ukur }\end{array}$ & $\begin{array}{l}\text { Uji } \\
\text { alat }\end{array}$ & $\begin{array}{l}\text { Alat } \\
\text { ukur }\end{array}$ \\
\hline 1 & Lampu & 220.25 & 220 & 0.45 & 0.45 & 0,99 & 0,99 & 98.01 & 98.12 \\
\hline 2 & Setrika & 219.70 & 220 & 1.78 & 1.91 & 0,99 & 0,99 & 372 & 365.2 \\
\hline 3 & $\begin{array}{l}\text { Kipas } \\
\text { angin }\end{array}$ & 221.15 & 221 & 0.20 & 0.21 & 0,99 & 0,99 & 44.09 & 42.01 \\
\hline
\end{tabular}

Berdasarkan hasil tabel pengujian pengukuran diatas dengan menggunakan beberapa beban-beban listrik seperti lampu jenis pijar yang memiliki daya 100 Watt, setrika yang memiliki daya 400 Watt dan kipas angin sebesar 45 Watt. Dari data di atas dapat dicari seberapa besar nilai daya dapat dibuktikan dengan menggunakan persamaan daya yaitu:

$\mathrm{P}=\mathrm{V} . \mathrm{I} . \operatorname{Cos} \varphi$

Dimana : P adalah daya aktif dengan satuan Watt $\mathrm{V}$ adalah Tegangan dengan satuan Volt I adalah Arus dengan stuan Ampere

$\operatorname{Cos} \varphi$ adalah besar sudut fasa

Dari data tabel 4.1 diatas terlihat perbandingan sangatlah kecil yakni untuk beban lampu 100 Watt mencapai $0.99 \%$ dan untuk beban setrika 400 Watt mencapai $1,5 \%$ dan pada beban kipas angin mencapai $1 \%$ dengan beban yang berbeda ini dapat disimpulkan alat ini telah lulus uji dan akan dipasang pada panel utama pada gedung Laboratorium Jurusan Teknik Elektro dan Gedung UPT- TIK Universitas Lampung.

\subsection{Back up daya}

Sistem monitoring ini adalah sistem yang dapat terus menerus memantau keadaan besaran listrik selama alat ini terpasang pada panel listrik utama yang tidak boleh terhenti memonitoring, dengan demikian lalat ini memerlukan suatu back-up daya yang dapat menyuplai daya pada saat terjadi mati lampu sehingga alat dapat memonitoring besaran listrik secara terus menerus.

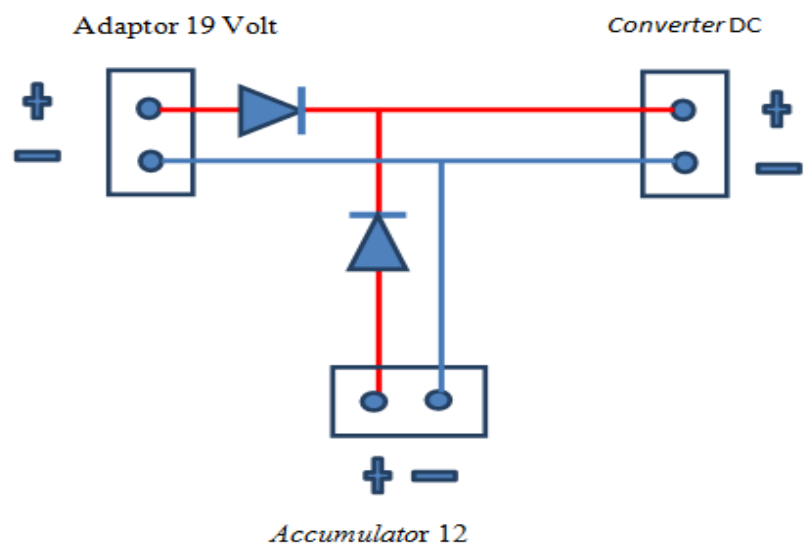

Gambar 8. Rangkaian Back Up Power Single Board Computer BCM2835

Rangkaian back up ini terhubung paralel antara adaptor 19 volt, converter DC dan accumulator 12 Volt sebagai inputan ke Single Board Computer BCM2835.

\subsection{Pengujian Sistem}

Penelitian ini akan dilakukan pada dua box panel listrik 3 fasa gedung LAB Jurusan Teknik Elektro dan Gedung UPT -TIK Universitas Lampung.

Berikut ini adalah langkah - langkah pengujian sistem:

1. Langkah awal adalah memasang masingmasing hardware yang telah dibuat dipanel box 3 fasa sebelum masuk ke beban. 
2. Langkah ini membuat Database sebagai tempat penyimpanan hasil monitoring disini menggunakan spees memori yang ada di gedung puskom.

3. Langkah ini memasang alat back-up daya pada masing-masing alat yang terpasang pada panel listrik sebagai power jika terjadi pemadaman listrik dari PLN.

4. Langkah ini kalibrasi ulang antara alat yang terpasang dengan alat ukur dangan alat yang terpasang pada panel supaya nilai yang terbaca pada database akurat dengan nilai besaran listrik yang sesungguhnya.

5. Langkah ini mendownload program haidiSQL dan Navicat premium sebagai tempat untuk memonitoring yang data yang berjalan pada database.

6. Langkah ini membuat web untuk memonitoring hasil pengukuran besaran listrik secara langsung dalam bentuk grafik yang tampil lebih kurang 3 detik secara terusmenerus.

\subsection{Data Hasil Pengujian}

4.5.1 Data Hasil Pengujian di Panel Gedung Laboratorium Jurusan Teknik Elektro Universitas Lampung.

1. Grafik arus pada panel gedung Laboratorium JTE

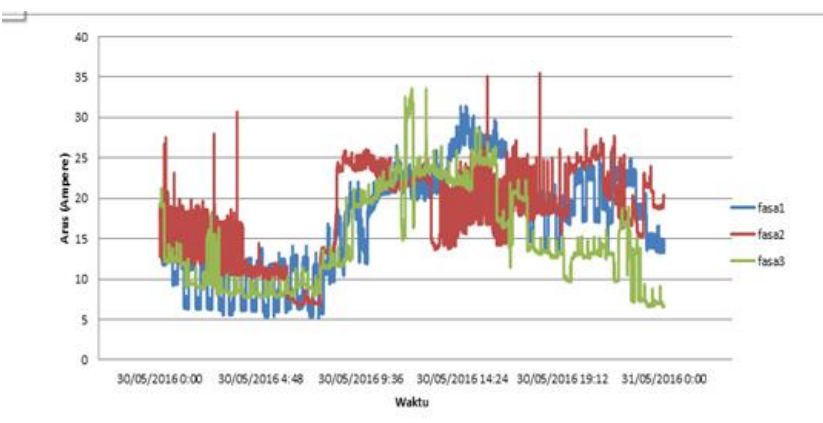

Gambar 9. Hasil monitoring arus lab tanggal 30 Mei 2016

Pada fasa 1, 2 dan 3 terlihat pada grafik menunjukan besar nilai arus sangatlah kecil sebesar 5 Ampere sampai dengan 10 Ampere hal ini disebabkan oleh pada jam 00.00 sampai dengan jam 08.00 beban yang terpakai hanya lampu saja sebagai penerangan, dan arus terbesar dengan nilai Arus hingga mencapai 35 Ampere ditunjukan pada ketiga fasa hal ini menunjukan bahwa banyaknya kegiatan mahasiswa di gedung LAB JTE dari jam 09.00 sampai dengan jam 22.00 malam.
2. Grafik daya pada panel gedung Laboratorium JTE

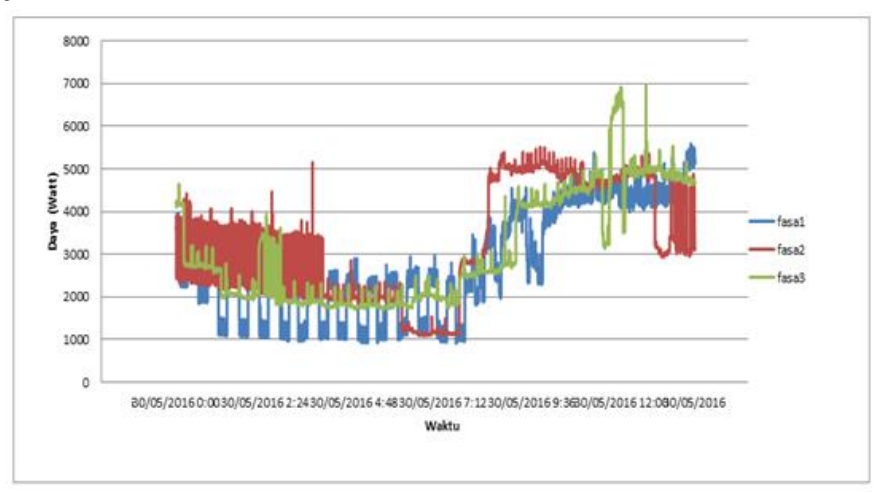

Gambar 10. Hasil monitoring daya lab tanggal 30 Mei 2016

Pada fasa 1 terlihat daya yang terukur pada fasa ini tidak setabil hal ini disebabkan oleh adanya beban induktif yang terpakai seperti beban pada AC. Daya yang terukur paling tinggi sebesar 5250 Watt pada jam 14.00. dan daya yang terendah sebesar 1000 Watt terjadi pada jam 00.00 sampai dengan jam 07.30 ini disebabkan oleh sedikitnya beban yang terpakai pada fasa ini.

Pada fasa 2 daya yang terukur sebesar 1000 Watt sampai dengan 5250 Watt. Dari daya yang terendah terjadi pada jam 04.00 sampai dengan jam 07.00 sebesar 1000 Watt hal ini disebabkan sedikitnya beban yang terpakai tetapi tidak berlngsung lama daya mulai naik kembali sekitar jam 10.00 sampai denag jam 14.00 siang, disini terlihat mulai banyaknya aktifitas mahasiswa yang menggunakan alat-alat listrik hingga dayanya mencapai 5250 Watt.

Pada fasa 3 terlihat penggunaan dayanya setabil dari jam 00.00 sampai dengan jam 08.00 sebesar 2000 Watt karena sedikitnya beban yang terpakai di malam hari namun pada siang hari pada fasa ini tampak jelas terlihat pada grafik nilai daya mulai naik dari 2000 Watt hingga mencapai daya tertinggi sebesar 7000 Watt.

3. Grafik faktor daya pada panel gedung Laboratorium JTE

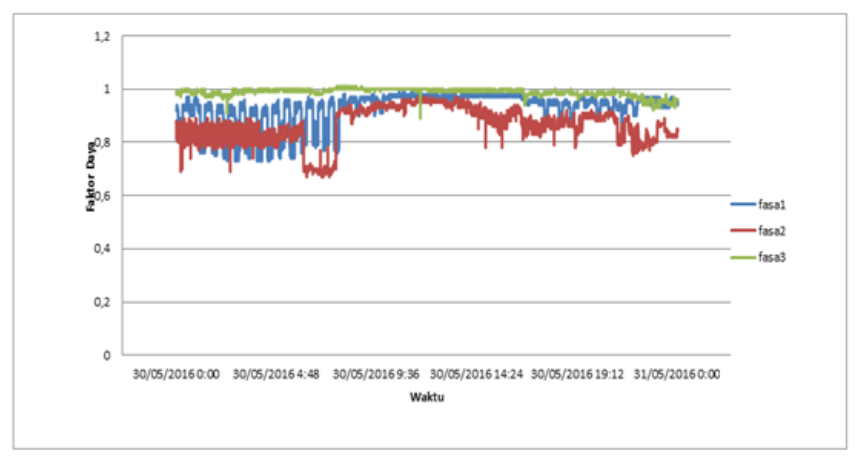

Gambar 11 Hasil monitoring faktor daya lab tanggal 30 Mei 2016 
Pada grafik-grafik diatas terlihat pada fasa 1 terlihat tidak setabil antara range $0.70 \mathrm{~s} / \mathrm{d} 0.99$ hal ini dikarenakan arus yang mengalir pada fasa ini tidak stabil. Pada fasa ke 2 terlihat cukup stabil dibandingkan dengan fasa ke 1 . Pada fasa ke 3 cosh phi nya mendekati 1 baik untuk beban. Pada gambar 4.8 terlihat ke 3 fasa nya mengalami penurunan faktor daya hal ini dikarenakan pada jam tersebut mengalami pemadaman listrik oleh PLN.

4. Grafik konsumsi energi $(\mathrm{kWh})$ pada panel gedung Laboratorium JTE

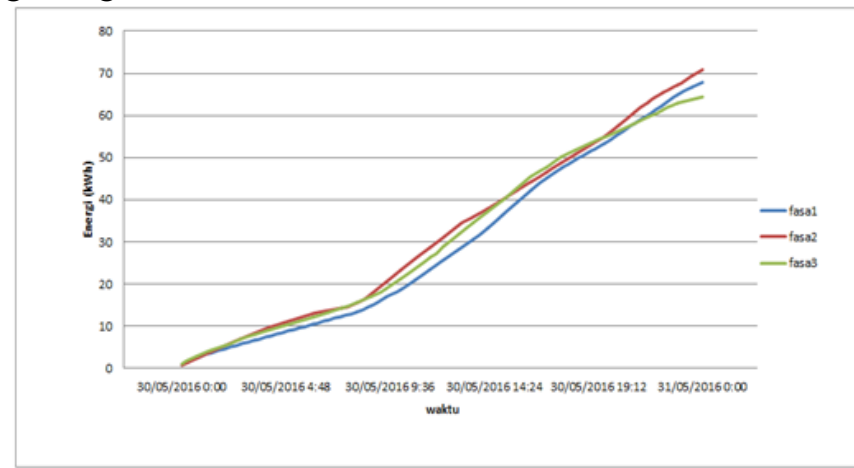

Gambar 12. Hasil monitoring konsumsi energi lab tanggal 30 Mei 2016

Dari Gambar 12. diatas menunjukan besar pemakaian konsumsi energi listrik yang terpakai selama 24 jam pada tanggal 30 Mei 2016

Besar konsumsi energi $=$ data awal - data akhir Sehingga:

Fasa $1=0 \mathrm{kWh}-67 \mathrm{kWh}=67 \mathrm{kWh}$

Fasa $2=0 \mathrm{kWh}-75 \mathrm{kWh}=75 \mathrm{kWh}$

Fasa $3=0 \mathrm{kWh}-63 \mathrm{kWh}=63 \mathrm{kWh}$

Dari persamaan besar konsumsi energi listrik diatas menunjukan pada fasa 2 terlihat lebih besar pemakaian bebanya sebesar $75 \mathrm{kWh}$ jika dibandingkan dengan kedua fasa lainya.

5. Grafik Tegangan (Volt) pada panel gedung Laboratorium JTE

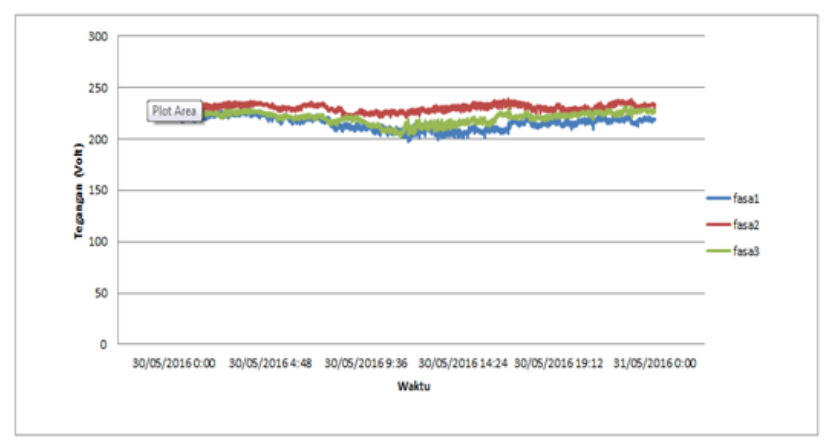

Gambar 13 Hasil monitoring tegangan lab tanggal 30 Mei 2016

Dari gambar terlihat pada ketiga fasa cenderung setabil tegangan terukur sebesar 220 Volt sampai dengan 225 Volt namun terlihat pada sekitar jam 07.00 sampai dengan jam 16.00 tegangan cenderung turun hingga mencapai 220 hal ini disebabkan oleh adanya beban-beban induktif yang terpakai pada hari kerja, tetapi tegangan tidak sampai turun masih dalam range listrik sehingga cukup aman bagi kelistrikan pada gedung lab JTE.

\subsubsection{Data Hasil Pengujian di Panel Gedung UPT - TIK Universitas Lampung.}

1. Grafik tegangan pada panel gedung UPT-TIK

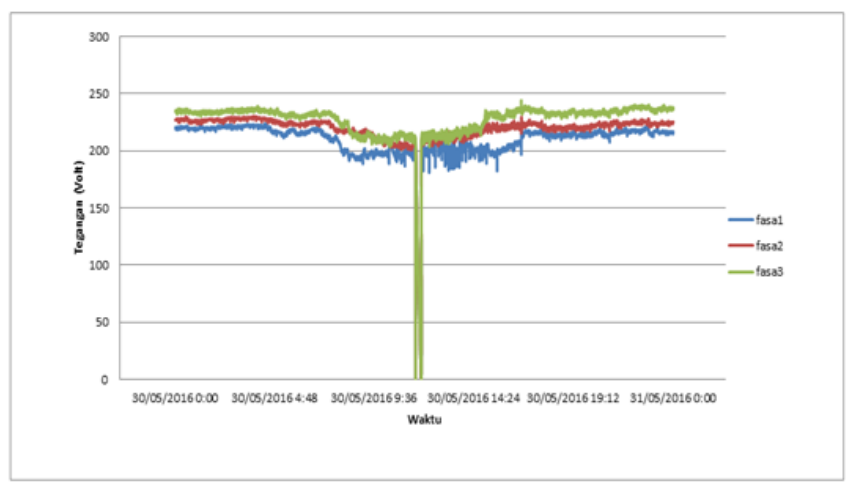

Gambar 14. Hasil monitoring tegangan gedung UPTTIK tanggal 30 Mei 2016

Terlihat tegangan pada ketiga fasa turun pada aktifitas mahasiswa dari jam 08.00 sampai dengan jam 16.00 sehingga tegangan sedikit menurun. Hal ini disebabkan oleh banyaknya beban-beban induktif yang terpakai pada jam kerja, karena beban induktif sangat berpengaruh dengan turunya tegangan. Terlihat ketiga fasa mengalami pemadaman listrik pada jam 10.00 sehingga tegangan menunjukan 0 Volt pada ketiga fasa.

2. Grafik faktor daya pada panel gedung UPT-TIK

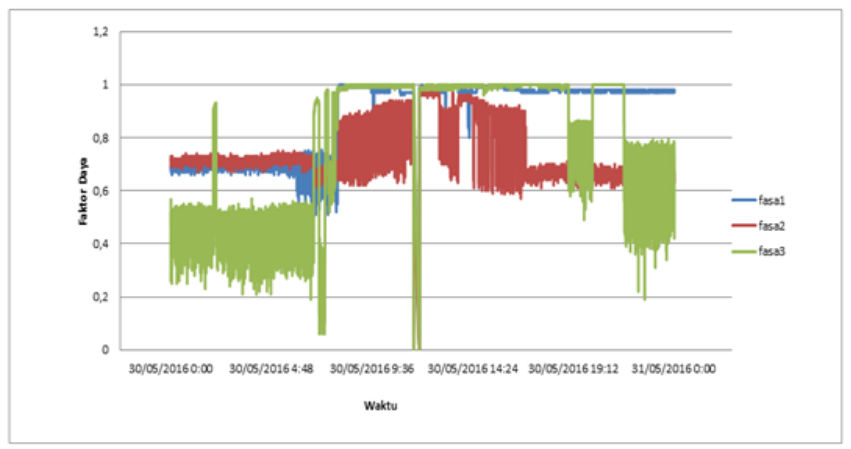

Gambar 15. Hasil monitoring faktor daya TIK tanggal 30 Mei 2016 
Dari grafik terlihat pada fasa 3 nilai faktor dayanya berubah-ubah tidak stabil berkisar antara 0,4 sampai 0,99 hal ini dipengaruhi oleh besar kecilnya nilai beban reaktif, sehingga jika nilai faktor daya tidak stabil dapat dimungkinkan adanya nilai daya reaktif. Pada fasa 1 cenderung stabil mendekati 1 terlihat

bahwa fasa berkisar antara 0,8 sampai 0,99 sehingga pada fasa ini sangat baik bagi kelistrikan.

3 .Grafik konsumsi energi (kWh) pada panel gedung UPT-TIK

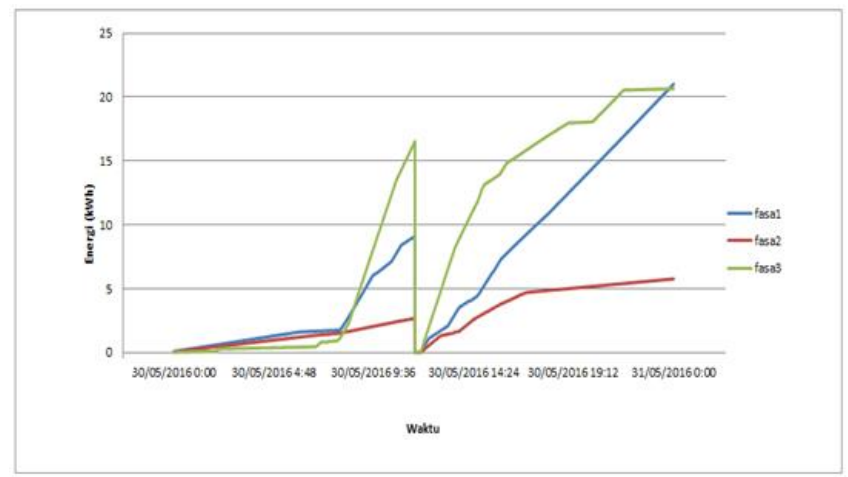

Gambar 15 Hasil monitoring kWh gedung UPT-TIK tanggal 30 Mei 2016

Jumlah total besar konsumsi energi adalah jumlah keseluruhan beban yang terukur dengan menggunakan persamaan di bawah ini:

Besar konsumsi energi = data awal - data akhir Sehingga:

Fasa $1=0 \mathrm{kWh}-(9 \mathrm{kWh}+22 \mathrm{kWh})=31 \mathrm{kWh}$

Fasa $2=0 \mathrm{kWh}-(5 \mathrm{kWh}+6 \mathrm{kWh})=11 \mathrm{kWh}$

Fasa $3=0 \mathrm{kWh}-(17 \mathrm{kWh}+21 \mathrm{kWh})=38 \mathrm{kWh}$

4.Grafik arus pada panel gedung UPT-TIK

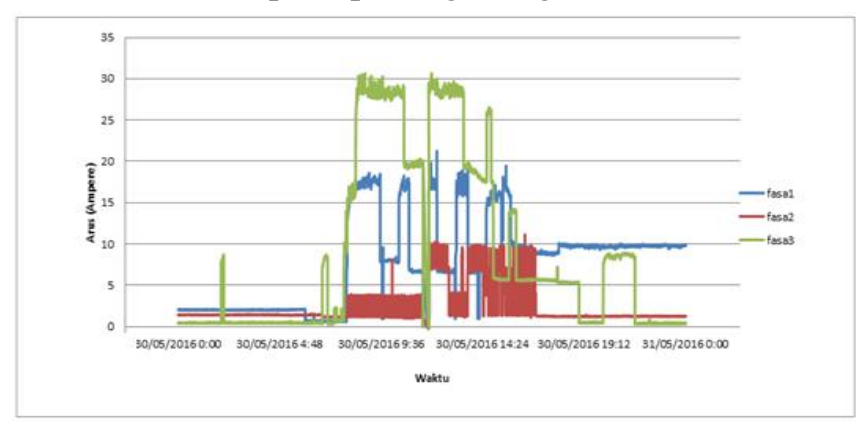

Gambar 16 Hasil monitoring arus gedung UPT- TIK tanggal 30 Mei 2016

Pada gambar 16 terlihat besar nilai arus yang terukur pada jam kerja tampak pada jam $06.00 \mathrm{~s} / \mathrm{d}$ jam 19.00 malam hal ini disebabkan oleh banyaknya beban yang terpakai pada ke 3 fasa tersebut. Arus listrik berbanding lurus dengan daya listrik, sehingga dapat dipastikan bahwa penyebab arus yang tidak seimbang adalah pemasangan beban yang tidak seimbang antara ketiga fasa, hal tersebut dibuktikan dengan bentuk grafik yang sama antara grafik monitoring arus grafik monitoring daya pada grafik daya.

5.Grafik daya pada panel gedung UPT-TIK.

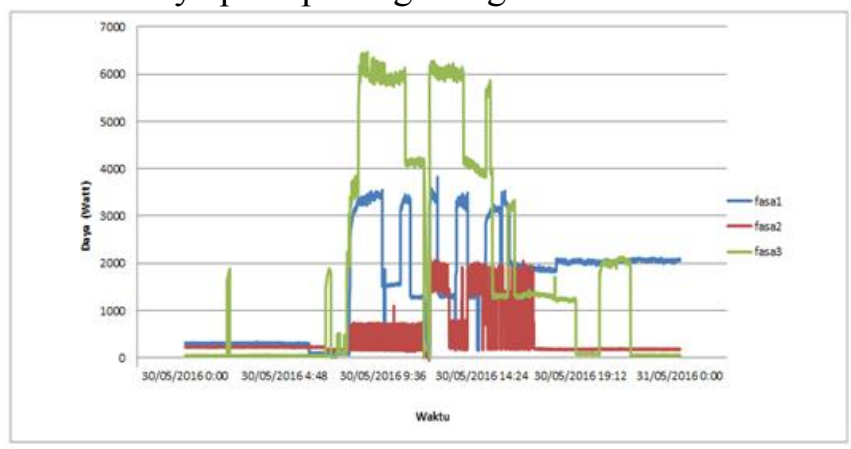

Gambar 17 Hasil monitoring daya gedung UPT-TIK tanggal 30 Mei 2016

Gambar 17 di atas merupakan grafik daya yang memonitoring besaran listrik daya yang terpasang pada panel utama gedung Puskom selama 24 jam pada tanggal 30 Mei 2016. Pada grafik ini besar daya yang terukur pada ke 3 fasa menunjukan banyak aktifitas besar pemakain pada jam 07.00 $\mathrm{s} / \mathrm{d}$ jam 16.00 terlihat daya yang sangat besar menunjukan pada fasa ke 3 pada grafik ini.

\subsection{Pembahasan}

Penelitian ini adalah membuat prototype sistem monitoring besaran listrik yang mampu menampilkan hasil monitoring ke web dan menyimpan hasil monitoring ke database. Besaran listrik yang dimaksud adalah tegangan (Volt), arus (Ampere), faktor daya (Cos $\theta$ ), daya (Watt) dan konsumsi energi $(\mathrm{kWh})$. Dalam pembuatan sensor tegangan, metode yang digunakan adalah dengan cara menurunkan tegangan tinggi $\mathrm{AC}$ dari 220 volt sampai dengan 5 volt dengan cara menurunkan tegangan menggunakan trafo step-down. Pada tugas akhir ini, digunakan trafo step-down karena lebih aman untuk rangkaian elektronika yang digunakan seperti arduino dan BCM 8235.

Untuk mendapatkan nilai arus, pada tugas akhir ini digunakan sensor arus CT-100A. Sensor tersebut dipilih karena memiliki sensitifitas tinggi dalam mendeteksi perubahan arus yang diukur dan sensor hanya menyensing saja yang cara pemakaianya hanya dikalungkan pada kawat panel yang terisolasi sehingga aman untuk pemasangan alat pada panel dengan kapasitas sensing 100 Ampere arus tersebut menunjukkan hasil pengukuran arus yang baik.

Untuk mendapatkan nilai konsumsi energi dan daya dapat dihitung secara manual dengan pehitungan, jika nilai tegangan, arus dan faktor daya diketahui selanjutnya nilai Daya dapat dihitung. Sebenarnya, jika telah tersedia sensor tegangan dan sensor arus cukup menambahkan sensor faktor daya maka nilai daya dan konsumsi 
Enegi dapat diketahui, sehingga tidak perlu menggunakan $\mathrm{kWh}$ meter. Namun saat ini belum tersedia sensor faktor daya yang dapat dihubungkan dengan Raspberry pi, dan cukup sulit untuk merancang sensor faktor daya tersebut.

Pengujian sistem dilakukan pada panel utama listrik 3 fasa Laboratorium Terpadu Teknik Elektro dan pada panel utama gedung Unit Pelayanan Teknis teknologi informasi dan komunikasi Universitas Lampung. Pada pengujian sistem ini ditemukan beberapa kendala yang menjadi kekurangan dari Hardware yang dibuat. Pertama adalah setelah Hardware dipasang pada panel listrik namun harus selalu melakukan proses kalibrasi setiap akan melakukan pengambilan data. Selanjutnya pada sensor arus yang dipasang pada panel sering sesekali menemukan kawat listrik pada panel listrik yang diameternya lebih besar daripada lubang diameter sensor arus sehingga menyulitkan proses pengambilan data pada panel tersebut. Kendala lainya adalah pada saat pengambilan data, data yang tersimpan di database harus sering membandingkan nilai yang tertera pada database dengan alat ukur manual dengan menggunakan alat ukur power clam meter yang disediakan pada laboratorium intstrumen dan pegukuran. dimana semakin banyak data yang terekam pada database maka akan selau timbul selisih nilai hal ini yang harus diwaspadai untuk selalu mengkalibrasi ulang alat tiap harinya.

Pada penelitian ini digunakan 2 buah Raspberry Pi untuk pemograman ke database dan WEB, pemograman tersebut cukup berat untuk dilajankan oleh sebuah komputer, sedangkan kemampuan Raspberry Pi terbatas yang hanya memiliki kapasitas 512 MB RAM.

Di setiap besaran listrik yang terukur pada dua gedung tidak mengalami kesulitan hal ini dikarenakan sensor arus dan sensor tegangan telah diuji sebelumnya hingga memudahkan untuk tugas akhir ini memasang dan mengukur pada panelpanel yang akan diukur besaran listriknya.

Untuk pembahasan besaran listrik seperti arus, tegangan, daya, faktor daya dan besar konsumsi energi listrik terhadap dua gedung yang di pilih untuk tugas akhir. Untuk besaran tegangan dan faktor daya sangatlah baik untuk sistem kelistrikannya, begitu pula dengan arus dan daya sangat baik bila dilihat dari nilai yang terukur pada grafik antara kedua gedung.

\section{KESIMPULAN DAN SARAN}

\subsection{Kesimpulan.}

Setelah dilakukan analisa data hasil pengujian dari alat yang dibuat, dapat disimpulkan beberapa hal sebagai berikut :
1. Prototype sistem monitoring ini dapat memonitoring besaran listrik langsung pada panel distribusi dari dua lokasi yang berbeda.

2. Prototype sistem monitoring ini membutuhkan back-up daya sehingga pada saat terjadi pemadaman listrik dari PLN alat ini akan mampu tetap bekerja.

3. Prototype ini dapat memonitoring besaran listrik seperti tegangan, arus, daya, faktor daya dan konsumsi energi listrik.

4. Dari data hasil pengujian sensor diketahui rata-rata error untuk pengukuran tegangan mencapai $0,78 \%$, pengukuran arus $12,03 \%$, pengukuran daya $4,84 \%$ dan pengukuran faktor daya $1,87 \%$. Jika dilihat dari persentase nilai arus terlihat lebih besar hal ini disebabkan karena arus sangat sensitif dengan beban yang terpakai.

5. Dari data yang didapat pada gedung laboratorim terpadu JTE pembagian beban beban yang dipakai tidak seimbang antar fasanya, maka dari itu untuk pembagian beban perfasanya harus dibagi dengan seimbang. Dan pada panel gedung UPT-TIK bahwa sistem kelistrikanya sangatlah baik, dari pembagian beban antar fasanya seimbang. Terlihat dari grafik - grafik besaran listrik pada bab IV. Dan dapat disimpulkan bahwa dari hasil pengukuran besaran listrik pada gedung UPT-TIK lebih baik pembagian beban antar fasa dibandingkan dengan gedung Laboratorium Terpadu Jurusan Teknik Elektro.

\subsection{Saran}

Agar sistem monitoring besaran listrik ini dapat dikembangkan, terdapat saran sebagai berikut:

1. Sistem yang dibuat masih menggunakan LAN sebagai koneksi ke server. Selanjutnya agar memudahkan dan lebih efisien disarankan untuk menggunakan Modul Ethernet Shield dan Modul wifi ESP 625.

2. Berdasarkan hasil monitoring pengukuran besaran lisrik pada gedung Laboratorium Terpadu Jurusan Teknik Elektro pembagian beban sangatlah tidak setimbang disarankan untuk usaha membuat beban menjadi setabil antar fasanya.

\section{DAFTAR PUSTAKA}

1. Besma, Dikpride Despa, Noer. S, “Rancang Bangun Alat Pemutus Aliran Daya Listrik Melalui Fasilitas SMS Berbasis Mikrokontroler', JITET, 2013. 
2. Fowler, Richard J. 2008. Electricity Principles \& Applications, Penerbit McGrawHill, New York.

3. Cekdin, Cekmas \& Taufik Barlian 2013 Rangkaian listrik, Penerbit ANDI, Jakarta.

4. Cisco, "Data Centre Power and Cooling", White Paper, p, 3, 2011.

5. D.A. Rusti, A. R. Nansur and M. Safrodin, "Monitoring Pemakaian Energi Listrik Berbasis Mikrokontroler Secara Wireless," EEPIS Repository, 2011.

6. Dikpride Despa, Ady Kurniawan, M. Komarudin, Mardiana, Gigih F N, Smart Monitoring of Electrical Quantities Based on Single Board Computer BCM2835", The 2nd International Conference on Information Technology, Computer, And Electrical Engineering (ICITACEE-2015), Semarang, Indonesia.

7. Dikpride Despa, Mardiana, Gigih F. N.,"Smart Monitoring Data Centre Base on Mini Single Board BCM 2835", The 1st International Conference on Science, Technology, and Interdisciplinary Research (IC-STAR), September 21 - 23, 2015, Bandar Lampung, Indonesia.

8. Dikpride Despa at.al, "PMU Based Monitoring and Estimation Power System Dinamic Stability Developed on 50-Hz Power System", Proceeding of Power and Energy System (AsiaPES 2012), 2012.

9. Dikpride Despa at.al, "PMU Based Monitoring and Estimation of Inter-area Power Oscillation for Singapore-Malaysia
Interconnection Power System", Journal of Energy and Power Engineering, USA, 2012.

10. Mardiana, Wahyu Eko S., et.al, "System Monitoring Server Berbasis SMS (Studi Kasus : Server Siakad Unila)", Electrician, Jurnal Rekayasa dan Teknologi FT Unila Vol.2, No.3, 2008.

11. Reza Pradikia, Achmad Affandi, Eko Setijadi, "Rancang Bangun Aplikasi Monitoring Jaringan dengan Menggunakan Simple Network Management Protocol", TEKNIK POMITS, Vol.2, No.1, pp. A 154 - A 15R, 2013.

12. Riyanto and R. O. Wayagi, "Sistem Monitoring Suhu Ruang Server Berbasis web dengan Menggunakan EZ430", Jurnal Ilmiah, Vol.2, No.1, pp. 50-54, 2011.

13. Pei Zhang, Fangxing Li, and Navin Bhatt, "Next-Generation Monitoring, Analysis, and Control for the Future Smart Control Centre", IEEE.

14. Thamrin, Ihsan. 2010. Perancangan $k W h$ Meter Digital Menggunakan Sensor Arus ACS712ELC-30A. Universitas Komputer Indonesia: Bandung.

15. Monitoring Besaran Listrik Dari Jarak Jauh Pada Jaringan Listrik 3 Fasa Berbasis Single Board Computer BCM-2835. (Adi kurniawan, 2015).

16. Rancang Bangun Sistem Monitoring Bandwidth, Koneksi Listrik dan Temperatur Ruang Berbasis Raspberry Pi pada Gedung Pusat Data Universitas Lampung (Hanang Priambodo, 2014). 